Dossiê

Ensino e Pesquisa em História ANTiga e História Medieval no Brasil

\title{
ROMA NO PERÍODO AUGUSTANO: A CONSTRUÇÃO MATERIAL E SIMBÓLICA DA CAPITAL DO MUNDO CONHECIDO
}

\author{
ROME IN THE AUGUSTAN AGE: THE MATERIAL AND SYMBOLIC \\ CONSTRUCTION OF THE CAPITAL OF THE KNOWN WORLD
}

Macsuelber de Cássio Barros da Cunha*

\begin{abstract}
RESUMO
Otávio Augusto se vangloriava de ter transformado Roma de uma cidade de tijolos para uma de mármore. Neste trabalho, dedicamos nossa atenção à estrutura material que deu sustentação à construção e ao desenvolvimento do poder de Augusto, ou seja, à cidade de Roma e às suas construçẽes. Temos como objetivo demonstrar a importância conferida ao solo sagrado de Roma, bem como o relevante papel que teve enquanto centro do poder e suporte para o desenvolvimento de uma arquitetura monumental; tratamos também sobre a visão de Roma enquanto capital do mundo conhecido, o que estava expresso de modo material em determinadas construções do período.
\end{abstract}

PALAVRAS-CHAVE: Augusto. Construçẽes. Roma.

\begin{abstract}
Octavian Augustus boasted that he had transformed Rome from a city of bricks to a city of marble. In this work, we focus on the material structure that underpinned the construction and development of the power of Augustus, that is, the city of Rome and its constructions, when we aim to demonstrate the importance conferred on the sacred ground of Rome, as well as the relevant role that had as center of the power and support for the development of a monumental architecture; we also deal with the vision of Rome as the capital of the known world, which was expressed materially in certain constructions of the period.
\end{abstract}

KEYWORDS: Augustus. Constructions. Rome.

\section{INTRODUÇÃO}

Roma, que a princípio era uma pequena cidade às margens do rio Tibre, se tornou a capital de um amplo Império territorial que se estendeu por diversas regiões próximas ao mar Mediterrâneo. Durante séculos, Roma foi o centro do poder e, mesmo mais tarde, quando deixou de ser a capital do Império, manteve sua importância e poder simbólico. A grandiosidade arquitetônica de suas construções

\footnotetext{
* Professor do Instituto Federal de Educação, Ciência e Tecnologia Goiano (IFGOiano), campus Trindade. Doutor em História pela Universidade Federal de Goiás (UFG). Membro do Laboratório de Estudos sobre o Império Romano (LEIRGO). E-mail: macsuelber@hotmail.com
} 
serviu de modelo ou inspiração para construções realizadas em diversas partes do Império Romano, que viam em Roma o modelo a ser seguido.

No período augustano, Roma desempenhou um papel importante, não apenas no que se refere a aspectos religiosos e ao seu poder simbólico, como também enquanto suporte para a utilização de uma arquitetura cada vez mais sofisticada e atrelada à política, à propaganda e à criação de uma imagem positiva de Augusto e de seu governo. Neste trabalho tratamos sobre esta temática, evidenciando a importância que a Vrbs, com seu solo sagrado, desempenhou no governo do Princeps. Uma das estratégias políticas utilizadas por ele para evidenciar esta importância foi a de propagar, de diversas formas, algumas das histórias relativas à fundação de Roma, se colocando como descendente de uma linhagem divina que estava intrinsecamente ligada a esta fundação, além de se associar com importantes personagens da história romana.

\section{AS ORIGENS DE ROMA E SUA IMPORTÂNCIA NO CONTEXTO AUGUSTANO}

De acordo com autores como Tito Lívio (História de Roma, I, 1-7), as origens de Roma se conectam com Eneias, que, ao escapar de Tróia com seu pai Anquises e seu filho Ascânio (Iulo), aporta na Península Itálica, onde posteriormente Ascânio funda a cidade de Alba Longa. Da linhagem real de Alba Longa descendem Rômulo e Remo, sendo este primeiro o fundador de Roma no ano de 753 a.C. ${ }^{1}$

As histórias sobre a fundação de Roma por Rômulo tiveram grande importância e estreita relação com o contexto augustano. De acordo com a crença romana, quando Rômulo e Remo disputavam para saber quem fundaria a nova cidade a questão foi resolvida por augúrio, pois Remo, sobre o Aventino, avistou seis abutres, enquanto Rômulo, sobre o Palatino, viu doze, de tal forma que a cidade de Roma foi inicialmente fundada sobre essa colina e não englobava. neste momento, as outras colinas (OVÍDIO, Fastos, IV, 809-820). Segue o relato Tito Lívio (História de Roma, I, 6, 4; I, 7, 1):

\footnotetext{
Como os irmãos eram gêmeos, e o respeito pela idade deles não podia determinar entre eles [quem fundaria a nova cidade], concordou-se que os deuses que tinham esses lugares em sua proteção deveriam escolher por augúrio quem deveria dar o nome à nova cidade, que deveria governá-la quando construída. Rômulo tomou o Palatino para a sua observação augural, Remo, o Aventino. Dizem que Remo foi o primeiro a receber um augúrio, do voo de seis abutres. O presságio já havia sido anunciado quando o dobro desse número apareceu para Rômulo. $]^{2}$
}

\footnotetext{
${ }^{1}$ Esta narrativa fundacional foi amplamente utilizada por Otávio Augusto, que buscou, dentre outras coisas, se associar a Rômulo. Podemos afirmar que as associações estabelecidas no período augustano se deram a partir de uma seleção das narrativas de fundação que melhor se adequavam à imagem que Augusto buscava construir, já que, como pontua T. P. Wiseman (2013, p. 243), existiam dezenas de lendas de fundação em Roma. Para citar apenas dois exemplos, Dionísio de Halicarnasso (Das Antiguidades Romanas, I, 72-73) conhecia quatorze lendas diferentes da fundação e Plutarco (Vidas Paralelas, Rômulo, I-II) menciona treze.

${ }^{2}$ Quoniam gemini essent nec aetatis verecundia discrimen facere posset, ut dii, quorum tutelae ea loca essent, auguriis legerent, qui nomen novae urbi daret, qui conditam imperio regeret, Palatium Romulus, Remus Aventinum ad inaugurandum templa capiunt. Priori Remo augurium venisse fertur, sex vultures, iamque nuntiato augurio cum duplex numerus Romulo se ostendisset.
} 
Os contornos da Roma de Rômulo se limitavam ao contorno quadrangular do Palatino, em torno do qual se estabeleceram o primeiro pomerium e as primeiras muralhas. A importância simbólica do Palatino no período de Augusto foi tanta que Otávio escolheu essa colina como morada. Sob seu governo, o Palatino passou por uma grande transformação arquitetônica. Após Augusto, o próprio termo que designa o monte, Palatium, serviu de origem ao termo "Palácio", que passou a designar a morada dos imperadores.

O Palatino possuía um grande significado e poder simbólico. Neste monte havia um templo dedicado à deusa Vitória, que, como veremos mais à frente, foi utilizada como um importante tema iconográfico pelo Princeps, de modo que as representações desta deusa estavam presentes nos mais variados suportes (moedas, relevos, estátuas etc.).

Próximo a este templo havia outro, dedicado à Magna Mater. ${ }^{3}$ Esta era a deusa protetora de Eneias no momento de sua fuga de Troia, de modo que, ao aportar na costa do Lácio, Eneias dirigiu suas preces a duas divindades: Júpiter do Ida e Cibele Frígia (VIRGÍLIO, Eneida, VII, 135-140). A deusa, consequentemente. se tornou protetora de Roma também.

Também era no Palatino que ficava a gruta Lupercal, onde Fáustulo encontrou a lendária loba amamentando os gêmeos Remo e Rômulo. O Lupercal foi restaurado por Augusto (Feitos do Divino Augusto, XIX) e abrigava uma estátua comemorativa antiga, em bronze, que representava a loba e os bebês. Esta restauração expressa a importância simbólica da gruta para a propaganda do Princeps, considerado o novo Rômulo.

Havia também a lendária cabana de Rômulo, que foi preservada como um monumento ${ }^{4}$ histórico ao longo da história romana. Foi próximo a ela que Otávio escolheu viver a partir de 43 a.C., quando passou a morar na modesta casa que havia sido de Hortênsio (SUETÔNIO, A Vida dos Doze Césares, Vida de Augusto, LXXII). Fazendo isso, sua imagem se associava à imagem de Rômulo enquanto fundador de Roma, o que ressoou na escolha do título dado ao Princeps, já que Rômulo foi uma das opções, sendo preterida pelo título de Augustus.

A história contava que quando Otaviano estava em campanha pelo seu primeiro
consulado em 43 a.C. seis abutres apareceram, e quando ele foi eleito mais seis
apareceram; este auspício, com seu eco do mito de Rômulo, indicou que ele também,
assim como Rômulo, (re)fundaria a cidade de Roma. Este tema foi mantido na
invenção do nome "Augusto", uma palavra anteriormente conhecida apenas como
epíteto (usado particularmente para lugares) com o significado de "consagrado por
augures". Como um nome ele evoca não apenas o favor dos deuses, mas também o
auspício que marcou a fundação de Roma (BEARD; NORTH; PRICE, 2004, p. 182).

\footnotetext{
3 O templo foi construído para abrigar a pedra negra que representava a deusa trazida da Frigia em 204 a.C. O templo foi dedicado em 191 a.C.

${ }^{4}$ Segundo Jacques Le Goff, "o monumentum é um sinal do passado. Atendendo às suas origens filológicas, o monumento é tudo aquilo que pode evocar o passado, perpetuar a recordação, [...]. Mas desde a Antiguidade romana o monumentum tende a especializar-se em dois sentidos: 1) uma obra comemorativa de arquitetura ou escultura: arco de triunfo, coluna, troféu, pórtico, etc.; 2) um monumento funerário destinado a perpetuar a recordação de uma pessoa no domínio em que a memória é particularmente valorizada: a morte. O monumentum tem como características o ligar-se ao poder de perpetuação, voluntária ou involuntária, das sociedades históricas (é um legado à memória coletiva) e o reenviar a testemunhos que só numa parcela mínima são testemunhos escritos" (LE GOFF, 1996, p. 535).
} 
Percebemos, assim, a importância da colina Palatina e de suas construções no que se refere à história romana e às narrativas de fundação. Tal carga simbólica foi amplamente utilizada por Augusto e por aqueles que propagavam a imagem do Princeps enquanto um novo Rômulo, refundador da cidade e fiel aos aspectos mais tradicionais da Res Publica. Esta parte do Palatino funcionava como um lugar de memória ${ }^{5}$, no qual essa memória é conservada e por meio do qual se evita o esquecimento. Mas, apesar de ter sido utilizada e manipulada por Augusto, em vista de objetivos particulares, esta memória não foi criada por ele ou por algum de seus contemporâneos:

\begin{abstract}
Naturalmente não se trata de uma sistematização mitológica e topográfica ocorrida em um breve período de tempo, nem de maneira unívoca. Evidentemente antigas memórias já ligavam esta parte do Palatino à fundação da cidade, memórias que tinham sido sacralizadas e, provavelmente, monumentalizadas já no fim do VI século e início do $\mathrm{V}$ século a.C., quando a colina já insere-se de modo claro numa organização urbanística de Roma, caracterizada pela regularização dos eixos de estradas e do arranjo dos edifícios sagrados. Em seguida, em correspondência à expansão militar e política de Roma no sul da Itália, se verifica um tipo de revisitação em chave troiana e mais amplamente helenizante das memórias antigas e dos monumentos sagrados a elas relacionados: pode-se supor que no final do século IV a.C. o arranjo dos lugares sagrados de Rômulo e a conexão entre Eneias e Rômulo já tinham ocorrido, mesmo se a lenda grega do desembarque de Eneias nas costas da Itália central já fosse conhecida, através da Magna Grécia e Campânia, no período Arcaico, e mesmo se o mito dos gêmeos tenha ao invés uma origem etrusco-itálico, em Roma remonta de novo ao século VI a.C. (PENSABENE, 2017, t.1, p. 5).
\end{abstract}

Desta forma, a cidade fundada por Rômulo se tornaria a capital do mundo conhecido. Autores do fim da República e início do Principado, numa visão retrospectiva, buscavam explicar a grandeza e o poder de Roma, procurando no passado os sinais de que Roma estava destinada à grandeza. Por exemplo, Virgílio, na Eneida, traça a história de Roma a partir de Eneias, de tal forma que todos os acontecimentos a partir daí apontariam para a grandiosidade que Roma alcançaria sob o governo de Augusto, numa espécie de grandeza prenunciada, pois relaciona o passado heroico de Roma e importantes figuras como Eneias, Vênus, Marte, Rômulo e Remo e outros com Augusto e seus feitos.

Antes de Virgílio, Cícero (Da Republica, II, 5-10) mostra a importância do lugar e de suas características para o desenvolvimento e grandiosidade de Roma. Nesta passagem, ele aborda a escolha do local para fundação de Roma, mostrando que Rômulo teve uma inspiração divina ao escolher um local distante da costa, onde estaria vulnerável a ataques surpresas; mas que possuía as vantagens das regiões litorâneas por estar à margem de um grande rio que flui para o mar:

Imaginando o lugar divinamente escolhido antes do desenvolvimento, os autores tardo-republicanos enumeraram seus atributos: boas fontes, colinas facilmente protegidas e pronto acesso ao mar ao longo do Tibre. Por sua vez, essa imagem produzida e idílica do início de Roma comunicava ideias sobre a cidade contemporânea. Não importava que o local original na verdade não fosse o ideal, com fluxos de águas salobras, um clima insalubre, um rio propenso a inundações e colinas

\footnotetext{
5 Para Pierre Nora (2008, p. 33-34), o que constitui os "lugares de memória", é um jogo de memória e história, uma interação dos dois fatores que leva à sobredeterminação recíproca. Para existir um lugar de memória tem que haver vontade de memória. Vontade esta que, como defendemos, esteve presente nas obras de Augusto, nas quais a memória trabalhava a fim de evitar o esquecimento de um passado exemplar e do nome e dos feitos do governante.
} 
facilmente atacadas, ou que a cidade do primeiro século a.C. estava gravemente carente de encantos. Abençoada pelos deuses, Roma tinha beleza inata (FAVRO, 2008, p. 45).

Em perspectiva semelhante, escreve Vitrúvio no Tratado de Arquitetura que dedica a Augusto. Ele explica a influência da posição geográfica e, consequentemente, do clima na formação dos povos. Para este autor, populações de regiões muito frias ou muito quentes seriam desfavorecidas pela natureza e possuiriam características como lentidão ou fraqueza, enquanto os romanos, por sua posição geográfica, não possuíam tais desvantagens:

Estando essas coisas assim dispostas no mundo pela natureza e sendo todas as nações diferentes perante as diversificadas misturas, o povo romano tem, na verdade, o seu território no centro do mundo e de todas as regiões da Terra. Com efeito, os povos apresentam-se na Itália muito equilibrados, tanto no que diz respeito aos membros corporais como ao vigor da inteligência em relação à força anímica. [...] a Itália, situada entre as zonas setentrional e meridional, possui, pelas misturas de uma parte e de outra, virtudes temperadas e invictas. [...] Assim, a divina mente dispôs a cidade do povo romano numa região escolhida e temperada, a fim de que se apoderasse do império do mundo (VITRÚVIO, Tratado de Arquitetura, VI, 1, 10-11). ${ }^{6}$

Outro autor do período augustano a tratar sobre a importância do solo sagrado de Roma é Tito Lívio (História de Roma, V, 50-55). Ao escrever sobre o saque que os Gauleses fizeram em Roma no ano de 390 a.C., esclarece que, após o saque, foi levantada a proposta de que os romanos deveriam se estabelecer na cidade etrusca de Veios, que havia sido conquistada há pouco tempo, ao invés de reconstruir Roma. Tito Lívio afirma que o general Marco Fúrio Camilo foi terminantemente contra esta proposta e desenrola um longo e empolgante discurso proferido por Camilo para demover o Senado da decisão, no qual enfatiza as vantagens naturais da localização da cidade, bem como suas fundações religiosas e a necessidade de os antigos cultos se localizarem em Roma, dentro das fronteiras sagradas:

Não sem razão, os deuses e os homens escolheram esse ponto como o local de uma cidade, com suas colinas saudáveis, o seu rio oportuno, pelo qual os produtos das regiões do interior podem ser levados e os fornecimentos extra marítimos obtidos; um mar próximo o suficiente para todos os fins úteis, mas não tão perto a ponto de estar exposto ao perigo de frotas estrangeiras; uma região no centro da Itália - em uma palavra, uma posição singularmente adaptada pela natureza para a expansão de uma cidade. [...] Aqui está o Capitólio, onde nos velhos tempos havia uma cabeça humana, e isso foi declarado como um presságio, pois naquele lugar seria fixada a cabeça e o supremo poder do mundo. Aqui foi que, enquanto o Capitólio estava sendo limpo com ritos augurais, Juventas e Terminus, para o grande prazer de seus pais, não se deixariam mexer. Aqui está o fogo de Vesta; aqui estão os escudos enviados do céu; aqui estão todos os deuses, que, se permanecerem, serão propícios a você (TITO LÍVIO, História de Roma, V, 54). ${ }^{7}$

\footnotetext{
${ }^{6}$ Cum ergo haec ita sint ab natura rerum in mundo conlocata et omnes nationes inmoderatis mixtionibus disparatae, ueros inter spatium totius orbis terrarum regionesque medio mundi populus Romanus possidet fines. Namque temperatissimae ad utramque partem et corporum membris animorumque uigoribus pro fortitudine stin Italia gentes. [...] eadem ratione Italia inter septentrionalem meridianamque ab utraque parte mixtionibus temperatas et inuictas habet laudes. [...] Ita diuina mens ciuitatem populi Romani egregia temperataque regione conlocauit, uti orbis terrarum imperii potiretur.

${ }^{7}$ Non sine causa di hominesque hunc urbi condendae locum elegerunt, saluberrimos colles, flumen opportunum, quo ex mediterraneis locis fruges deuehantur, quo maritimi commeatus accipiantur, mari uicinum ad commoditates nec expositum nimia propinquitate ad pericula classium externarum, regionum Italiae medium, ad incrementum urbis natum unice locum. [...] hic Capitolium est, ubi quondam capite humano inuento responsum est eo loco caput rerum summamque imperii fore;
} 
Esta passagem de Tito Lívio, mais do que esclarecer um acontecimento do século IV a.C., ao ressaltar a importância do local onde Roma tinha sido fundada e de suas fronteiras sagradas, reflete o imaginário de sua época,. Tito Lívio escreveu sua obra na década de 20 a.C. Anteriormente, na época em que César empreendeu o melhoramento de Roma através da arquitetura, criou-se o rumor de que ele, assim o fazendo, demonstrava que a cidade não era boa o suficiente para ele, e o seu relacionamento com Cleópatra agravou ainda mais tais rumores. Pairava no ar o receio de que o centro do poder deixasse Roma em direção a Alexandria. Rumores semelhantes giraram em torno de Antônio e seu relacionamento com Cleópatra, principalmente após Otávio ter lido o testamento de Marco Antônio, que estava com as Vestais, o qual expressava seu desejo de ser enterrado junto a Cleópatra. Esta informação foi propagada por Otávio de modo a criar uma imagem positiva de si próprio, na medida em que atacava a imagem do outro, representado enquanto traidor dos costumes próprios de Roma:

A preservação da centralidade de Roma e a garantia do elusivo fenômeno da identidade Romana continuaram a ser o ponto de manipulação nos anos finais da República. Otávio, o jovem herdeiro de Júlio César que foi mais tarde nomeado Augusto, alinhou-se com a cidade e todas suas tradições. A propaganda de Otávio contrapôs isso com a deslealdade de seu oponente Antônio que caiu sob a influência oriental de Cleópatra e da realeza (HOPE, 2005, p. 72).

Em razão disso, uma das primeiras medidas que Otávio tomou ao voltar a Roma, em 29 a.C., após vencer Marco Antônio e Cleópatra, foi iniciar a construção de seu próprio mausoléu. Tal atitude seria uma forma de deixar clara sua intenção de ser enterrado em Roma, afastando, assim, qualquer possibilidade de que acontecesse com ele o mesmo que aconteceu com César e com Antônio. Seu mausoléu era "um contraste agudo ao desejo de Antônio, uma afirmação arquitetural que garantia a presença contínua de Otávio em Roma, após sua morte, e declarava que a capital não poderia ser movida" (HASELBERGER, 2007, p. 50).

Esta iniciativa de Augusto, bem como outros atos do Princeps ao longo de seu governo, refletem o imaginário da época, expresso por autores como Cícero, Vitrúvio, Estrabão, Virgílio e Tito Lívio, que destacaram a importância do local de fundação de Roma e a necessidade (como expresso no discurso de Camilo) de manter Roma como o centro do poder, prestando a devida reverência ao solo sagrado de Roma.

\section{ROMA E A IMPORTÂNCIA DE SEU SOLO SAGRADO}

No que se refere à sacralidade do solo de Roma, devemos destacar que não apenas o terreno onde se localizavam os templos era sagrado, mas todo o espaço da cidade; ou, para ser mais exato, todo território que se localizava dentro do pomerium era um território consagrado, visto que o pomerium demarcava os limites sagrados da cidade, auguralmente definidos.

hic cum augurato liberaretur Capitolium, Iuuentas Terminusque maximo gaudio patrum uestrorum moueri se non passi; hic Vestae ignes, hic ancilia caelo demissa, hic omnes propitii manentibus uobis di. 
Além disso, o pomerium delimitava não apenas as fronteiras religiosas, mas também as fronteiras jurídicas da cidade. As fronteiras religiosas se referem à delimitação do templum, todo espaço ritualmente inaugurado; e as fronteiras jurídicas se referem à separação do domínio dos magistrados com Imperium, poder de comando militar que não poderia ser usado dentro do pomerium.$^{8}$

De acordo com Roger Antaya (1980, p. 185), nem mesmo os antigos tinham certeza quanto ao significado da palavra pomerium, sua etimologia e suas origens. Varrão (Da língua Latina, V, 32), que escreve na época de Augusto, afirmava que, ao fundar novas cidades, o ato de delimitar o pomerium se ligava ao rito etrusco de perfurar o solo com o arado, delimitando o terreno. Assim, pomerium derivaria de postmoerium, que significava o espaço atrás da muralha, ou seja, no interior dos muros. Outra etimologia possível seria promoerium, que, ao contrário da anterior, seria o espaço deixado livre próximo à muralha, mas do lado de fora. Para Tito Lívio (História de Roma, I, 44, 4), no entanto, pomerium seria o espaço deixado livre em ambos os lados da muralha, delimitando as fronteiras sagradas, de modo que seria mais correto falar em circamoerium.

Seja como for, o pomerium representava o espaço consagrado pelos áugures cujas restrições jurídicas e religiosas deveriam ser respeitadas. A importância e o respeito conferidos ao pomerium eram enormes. Como vimos, de acordo com a crença romana, quando Rômulo e Remo disputavam para saber quem fundaria a nova cidade, a questão foi resolvida por augúrio, pois Remo, sobre o Aventino, avistou seis abutres, enquanto Rômulo, sobre o Palatino, enxergou doze. O pomerium, que no princípio não englobava muito mais que o Palatino, foi sendo ampliado ao longo do tempo. ${ }^{9}$ No período de Augusto, o pomerium continuou a ser uma importante linha divisória entre diferentes tipos de atividades humanas e entre tipos diferentes de relações humanas com os deuses.

É importante destacar a reserva, por parte dos romanos, em construir templos a divindades estrangeiras dentro do pomerium, de modo que alguns destes templos acabaram sendo construídos no Monte Aventino, ou seja, dentro da muralha, mas fora do pomerium ${ }^{10}$ Sobre este aspecto devemos lembrar que, assim como esclarece Eric Orlin (2002, p. 2), "não havia regra excluindo cultos estrangeiros de dentro do pomerium," O único texto antigo que possuímos que traça as regras de localização de templos

\footnotetext{
${ }^{8}$ Michel Labrousse (1937, p.166) trata sobre a delimitação das fronteiras religiosas e jurídicas, estabelecendo uma distinção entre Imperium Domi e Imperium Militiae. Sobre esta noção de Imperium Domi, Fred Drogula (2007, p.420) defende a tese de que a mesma deve ser descartada, pois segundo ele, Imperium era um poder essencialmente militar, não podendo ser associado a um poder civil, para tal noção ele se utiliza do termo Potestas, que relaciona com os poderes civis dos magistrados.

${ }_{9}^{9}$ Segundo James H. Oliver (1932, p.147), não sabemos praticamente nada sobre as extensões no período da Realeza, exceto a tradição de que o pomerium era estendido de tempos em tempos. Para este autor, do período da República até a época de Cláudio, os autores antigos atribuem as extensões a Sula, Júlio César e Augusto. Por meio das fontes escritas e de achados arqueológicos (como os cippi do período de Cláudio e de Vespasiano que foram encontrados e que serviam para marcar os limites pomeriais), sabe-se que Cláudio realizou uma extensão em 47/48 d.C., Vespasiano e Tito ampliaram o pomerium em 75 d.C. e Adriano restaurou o pomerium deles em 121 a.C. Apesar de Augusto ser citado como um dos que expandiram o pomerium, não há um consenso com relação a isso entre os pesquisadores, de modo que Michel Labrousse (1937, p.174) refuta os argumentos de Oliver e não acredita que Augusto tenha feito tal expansão. Segundo Mary T. Boatwright (1986, p.14), “a avaliação do testemunho literário e documental sugere que o próprio Cláudio foi o responsável tanto pela tradição referente à extensão pomerial de Augusto quanto por uma associação talvez nova, mas decididamente enfática, de extensões pomeriais com a expansão do território romano." Para esta autora esta seria uma criação de Cláudio como uma forma de associar seu nome com o de Augusto.

${ }^{10}$ Somente com o Imperador Cláudio e sua expansão do pomerium (49 d.C.) é que o Aventino passou a ser englobado dentro das fronteiras sagradas de Roma (BOATWRIGHT, 1984, p. 37).
} 
é a obra de Vitrúvio (Tratado de Arquitetura, I, 7, 1), na parte em que ele discorre sobre a melhor localização para os templos de determinados deuses na construção de novas cidades. No entanto, ele usa como critério as características dos deuses e não menciona o fato de ser ou não um deus de "origem estrangeira". Apesar de Vitrúvio não citar o pomerium, propriamente dito, como aspecto definidor da localização de templos, mas sim a muralha e as instruções deixadas pelos “arúspices etruscos, nos escritos da sua ciência", acreditamos que na obra de Vitrúvio uma coisa e outra têm o mesmo valor. Ao se utilizar da muralha como linha que demarcava o território das novas cidades, Vitrúvio o fazia devido ao fato de que, na fundação de novas cidades, de acordo com o rito etrusco, o lugar no qual se erguiam as muralhas e a linha divisória do pomerium praticamente coincidiam. Isso pode ser percebido em outros autores do mesmo período como, por exemplo, Varrão (Da Língua Latina, V, 32) e Tito Lívio (História de Roma, I, 44. 4), que, ao tratarem sobre o pomerium, esclarecem que de acordo com os ritos etruscos, após as cerimônias para a delimitação do espaço sagrado destinado à cidade, uma muralha era erguida.

\section{A CIDADE E SUAS CONSTRUÇÕES}

Além deste aspecto referente ao pomerium, em se tratando de cidade e ao modo de projetá-la, de acordo com Lewis Mumford (1998, p. 228), os romanos foram influenciados, em muitos aspectos, pelos etruscos. Da acrópole da cidade etrusca se tomavam os augúrios sagrados antes que uma cidade pudesse ser fundada. A prática foi adotada pelos romanos que, antes de fundar novas cidades, além de tomar os augúrios, realizavam o traçado dos contornos da cidade:

Não pode haver dúvida de que os romanos estavam cientes do conceito da cidade planejada. [...] a Arqueologia revela a localização e o traçado cuidadosamente planejados das colônias do fim da República. Havia agrimensores profissionais e, no Império pelo menos, arquitetos profissionais. Desde o início, uma nova cidade foi dotada de defesas adequadas, com edifícios públicos essenciais como o templo e o fórum, com um abastecimento de água - sem o qual uma cidade não poderia ser considerada habitável - e seu sistema concomitante de drenos, com ruas pavimentadas e com os magistrados que têm jurisdição sobre essas coisas (ROBINSON, 1994, p. 12).

No período de Augusto, Vitrúvio desenvolveu instruções destinadas à construção de novas cidades. No primeiro livro do seu De Architectura, após refletir sobre a formação do arquiteto e sobre as partes que compõem a arquitetura (capítulos 1, 2 e 3), ele dedica os últimos capítulos (4 ao 7) para abordar a construção de novas cidades. Desta forma, do $4^{\circ}$ ao $7^{\circ}$ capítulo do primeiro livro, Vitrúvio trata desde a escolha dos lugares para a fundação de cidades, construção de muralhas, distribuição de ruas, até a escolha dos lugares destinados aos templos e outros edifícios públicos.

No período de Augusto "muitas cidades na Itália adquiriram um conjunto "padrão" de instalações - teatro, anfiteatro, banhos, fórum, prédios públicos - uma visão de cidade como apresentada por Vitrúvio no De Architectura" (LOMAS, 2005, p. 29). No que se refere à organização urbana e ao traçado de suas ruas, Roma não poderia ser vista como modelo a ser seguido, por ser desordenada e 
dispersa devido ao seu crescimento e superpopulação. De acordo com Tito Lívio (História de Roma, V, 55, 4-5), a explicação para a falta de ordem no que se refere ao traçado de Roma foi o fato de ela ter sido reconstruída, após o ataque dos gauleses, às pressas e sem um plano norteador, o que deu à cidade a aparência "como se o terreno tivesse sido apropriado e não dividido."

No entanto, no que se refere às construções e edifícios públicos, Roma era o grande referencial a ser seguido e emulado. Mesmo aquelas regiões conquistadas por Roma, cuja infraestrutura urbana já estava consolidada antes da conquista, buscava-se construir edifícios públicos segundo o modelo romano, erigindo, assim, templos, pórticos, teatros e diversas outras obras presentes em Roma, edifícios estes que deveriam compor uma cidade ideal.

Esta perspectiva de uma cidade ideal, possuindo determinados edifícios públicos, pode ser percebida em outros autores antigos. Para Pausânias (Descrição da Grécia, X, 4, 1-4), existiam dois fatores que determinavam o status urbano a um assentamento: o primeiro era a existência de uma série de edifícios públicos que engrandecia sua aparência, além de oferecer comodidade aos habitantes; e o segundo era o meio pelo qual a cidade se relacionava politicamente com o mundo externo. Podemos perceber, com o primeiro fator, a importância dos edifícios públicos enquanto garantidores da identidade urbana, sem os quais um território habitado por um grupo de pessoas não poderia possuir o status urbano. Além disso, a importância do território e da presença de diversos edifícios públicos residia no fato de que era exatamente esse o principal requisito para se determinar a civilização. A falta desta infraestrutura, a falta da cidade em si, era sinônimo de selvageria.

\section{A INFRAESTRUTURA ROMANA}

Augusto se empenhou em manter a tradição de valorização do espaço urbano, seguindo os passos de César e de outros grandes homens do passado, que se dedicaram a melhorar a paisagem arquitetônica de Roma, conferindo a ela a monumentalidade que a capital do Império merecia. A Vrbs foi o palco escolhido por Augusto para desenvolver, por meio da arquitetura, um melhoramento e sofisticação da paisagem urbana. Com isso, Roma passou a ser não apenas um símbolo de esplendor e grandeza, como também se constituía em uma verdadeira lição visual sobre a história romana, já que cada construção estava ligada a acontecimentos lendários ou históricos, recontando a história de Roma desde suas origens até o momento em que, sob seu governo, Roma alcançava novamente um tempo de paz e prosperidade, tal como foi propagado no período.

Desta forma, a cidade era o suporte sobre o qual se erigiam expressivos complexos arquitetônicos, que além de servir às funções religiosas, políticas, de sociabilidade etc., serviam também como uma importante ferramenta política nas mãos de Augusto. Por meio do melhoramento arquitetônico de Roma, ele demonstrava o seu cuidado e interesse nas relações com as divindades, bem como com a vida dos cidadãos e habitantes de Roma, que passaram a viver numa cidade cada vez mais monumental e rica, devido ao influxo de riquezas advindas de outras partes do Império. 
O que em outras regiões era considerado um luxo, em Roma estava à disposição de todos, como, por exemplo, a abundância de água trazida às fontes pelos aquedutos reformados ou construídos por Augusto e Agripa. Ou o sistema de drenagem e esgoto da Cloaca Máxima, obra grandiosa iniciada por Tarquínio Antigo e terminada por Tarquínio Soberbo. Tal sistema de drenagem e esgoto foi revitalizado por Agripa, que, como conta Dion Cássio (História Romana, XLIX, 43, 1), após limpá-lo, teria navegado em seus canais até o Tibre.

No que se refere à água trazida pelos aquedutos, Plínio, o Velho, deixa clara a admiração que possuía com relação aos feitos dos romanos neste aspecto. Para ele, nada era mais digno de admiração que isso:

Se considerarmos apenas o abundante abastecimento de água ao público, para banhos, piscinas, canais, fins domésticos, jardins, lugares nos subúrbios e casas de campo; e depois refletir sobre as distâncias que são percorridas, os arcos que foram construídos, as montanhas que foram perfuradas, os vales que foram nivelados, devemos, necessariamente, admitir que não há nada a ser encontrado mais digno de nossa admiração em todo o universo (PLÍNIO, O VELHO, História Natural, XXXVI, 123). ${ }^{11}$

As vias romanas são exemplos, também, da grandiosa infraestrutura que permitiu o desenvolvimento da grandeza de Roma e que recebeu a devida atenção de Augusto e de seus aliados. As vias romanas, estradas que irradiavam de Roma, desde o seu início, nas portas romanas, até a chegada ao seu destino designado, sempre receberam a atenção das autoridades romanas. Durante a República, os magistrados construíram uma rede de estradas, potente declaração do poder romano sobre as paisagens conquistadas. Augusto seguiu o exemplo, reconhecendo a importância de boas estradas para controlar seu Império e maximizar a passagem de bens e pessoas.

Como nos lembra Favro (2008, p.111-112), Roma era uma cidade de consumo e por isso o acesso a ela era essencial. As estradas, as ruas e o rio tiveram que ser mantidos para garantir o movimento de alimentos, materiais de construção e tropas, de modo que, pouco depois de ser nomeado Augusto, o Princeps voltou sua atenção para o sistema de transporte de Roma, iniciando reparos na Via Flamínia ao norte da cidade. Para demonstrar sua magnanimidade, ele colocou estátuas de si mesmo sobre os arcos ao longo da grande via. Além disso, no ano de 20 a.C., ele assumiu o cargo de Cura Viarum. Para comemorar o melhorado sistema de manutenção viária, Augusto criou o Milliarium Aureum, localizado no Fórum Romano. Tal monumento foi concebido como um ponto onde todas as estradas convergentes em Roma se encontraram. Era, certamente, um monumento sob a forma de um marco romano feito ou revestido de bronze dourado, mas parece não haver suporte em nossas fontes para a noção de que tenha contido a inscrição com os nomes das principais cidades do Império (ou da Itália) e as distâncias destes em relação a Roma. O Milliarium Aureum marcou o ponto de encontro simbólico e o coração do Império (RICHARDSON, 1992, p. 252).

\footnotetext{
${ }^{11}$ Quod si quis diligentius aestumauerit abundantiam aquarum in publico, balineis, piscinis, euripis, domibus, hortis, suburbanis uillis, spatia aquae uenientis, exstructos arcus, montes perfossos, conualles aequatas, fatebitur nil magis mirandum fuisse in toto orbe terrarum.
} 
As obras de infraestrutura que foram melhoradas por Augusto permitiram o desenvolvimento da cidade de Roma e sua grandeza, de tal modo que Estrabão elogiou a prudência romana ao conferir importância a tais empreendimentos:

Acredita-se que as cidades gregas tenham florescido principalmente por causa da feliz escolha feita por seus fundadores, em relação à beleza e à força de seus lugares, à proximidade de algum porto e à excelência do país. Mas a prudência romana era mais particularmente empregada em assuntos que receberam pouca atenção dos gregos, como pavimentar suas estradas, construir aquedutos e esgotos, para transportar os esgotos da cidade para o Tibre. Na verdade, eles pavimentaram as estradas, atravessaram colinas e encheram vales, de modo que a mercadoria pode ser transportada a partir dos portos. Os esgotos, arqueados com pedras cortadas, são suficientemente grandes em algumas partes para que os vagões carregados de feno passem; a água é trazida para a cidade através dos aquedutos em quantidades tão grandes que pode-se dizer que os rios atravessam a cidade e os esgotos; e quase todas as casas têm cisternas, canos e fontes abundantes (ESTRABÃO, Geografia, V, 3, 8). ${ }^{12}$

Além disso, as riquezas trazidas a Roma após as conquistas territoriais conseguidas por este governante estavam ao alcance dos olhos de todos. Todos aqueles que adentrassem nos novos templos ou em outros edifícios públicos construídos sob as suas ordens participavam, de certo modo, de uma riqueza compartilhada (pelo menos simbolicamente), pois poderiam, por exemplo, caminhar sobre pavimentos feitos com riquíssimos mármores vindos de diversas partes do Império. Com isso os romanos poderiam se sentir como senhores do mundo. De acordo com Richard Beacham (2007, p. 151), "governante e governados foram exortados pelos símbolos, mitologia, poesia, arte e arquitetura da época a conceber-se como atores em um grande desfile histórico: a expansão, a perfeição e a celebração do poder romano e da conquista romana."

Podemos perceber, assim, a importância que a cidade possuía no imaginário existente no período augustano e, juntamente a isso, as estratégias desenvolvidas por Augusto para expressar seu interesse pelo bem comum. Isso foi demonstrado a partir de um grande esforço de sua parte para desenvolver em Roma uma arquitetura grandiosa que conferisse à cidade os requisitos necessários para que se tornasse digna de ser a capital do mundo conhecido, a sede do poder imperial e a casa do Imperador, ornando-a, como convinha à grandiosidade do Império, com os mais belos exemplares arquitetônicos, carregados com uma decoração rica de detalhes esculpidos em preciosos mármores.

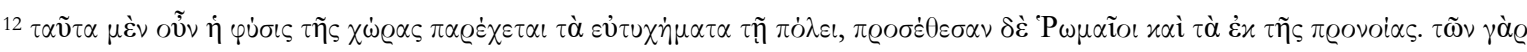

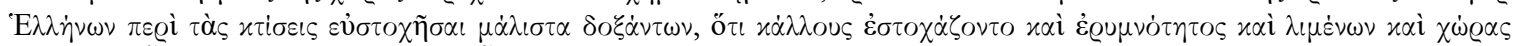

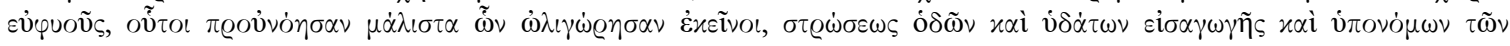

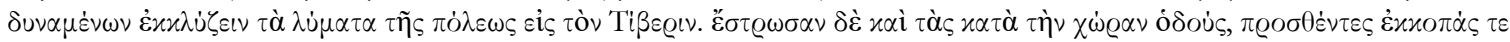

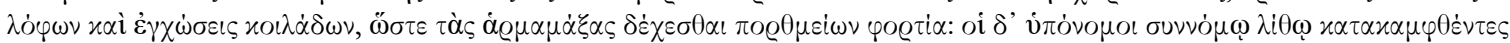

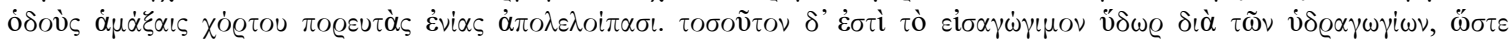

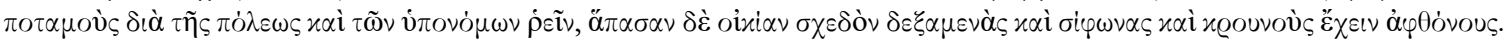




\section{ROMA, A CAPITAL DO MUNDO CONHECIDO}

Com a atuação de Augusto, deve ter ficado claro a todos os romanos que Roma não era uma simples cidade, mas verdadeiramente a capital do mundo conhecido. E esta era a crença da época, a de que Roma dominava, com pouquíssimas exceções, todas as regiões do mundo, pelo menos do mundo tal e qual eles concebiam. Tal crença é expressa, por exemplo, no prefácio das Res Gestae na qual se afirma "Abaixo uma cópia dos feitos do Divino Augusto, pelos quais submeteu o mundo ao império do Povo romano" (Feitos do Divino Augusto, Pr.). ${ }^{13}$ Algo muito parecido foi escrito, décadas antes, por Vitrúvio, no De Architectura: "Havendo a tua divina mente e a tua grandeza, ó Imperador César, submetido o mundo com Império (VITRÚVIO. Tratado de Arquitetura, I, Pr, 1). ${ }^{14}$ Percebemos, nestes dois trechos, a noção de que, com Augusto, o mundo estava submetido ao poder de Roma, de tal forma que esta era literalmente a capital do mundo.

Representações associadas a esta temática de poder sobre o mundo podiam ser vistas em Roma, como, por exemplo, no acrotério que se localizava no alto da Cúria Júlia e que representava a Vitória sobre um globo. Diversos denários do período (RIC I 254a, RIC I 254b, RIC I 255) traziam no reverso a representação da vitória sobre o globo. Também podemos ver uma representação semelhante em áureos da época (29/27 a.C.), como, por exemplo, no aureus (RIC I 268. Figura 1), cunhado provavelmente em Roma, no qual vemos, em seu anverso, a cabeça de Otávio e no reverso, entre a inscrição IMP CAESAR, a representação da Vitória em pé sobre o globo, com as asas abertas, segurando uma grinalda na mão direita e um estandarte na esquerda, apoiado sobre o ombro esquerdo. Em tais moedas, fica clara a associação da imagem de Augusto com a Vitória sobre o orbis terrarum, simbolizando o poder e domínio de Augusto sobre as diversas regiões do mundo conhecido.

Figura 1 - Moeda de Ouro. Áureo. RIC I 268.

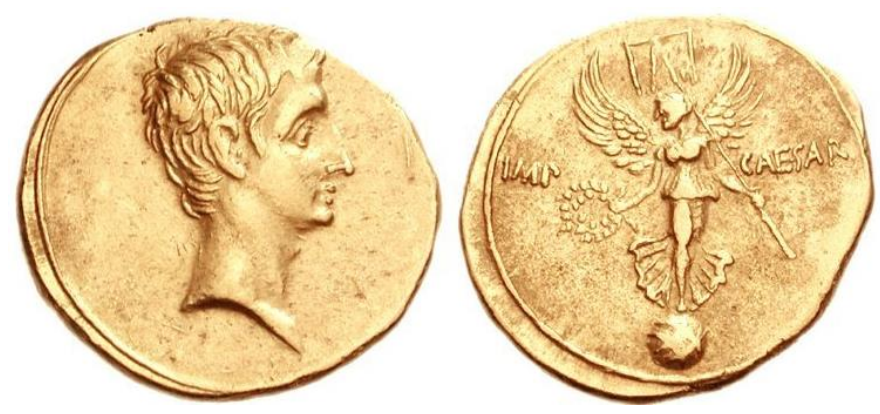

Fonte: The British Museum, Londres, Inglaterra.

Ao visualizar um mapa moderno com as regiões dominadas por Roma no período de Otávio Augusto, podemos vislumbrar a grandeza e a abrangência de seu vasto Império territorial. Mas, ainda assim, temos uma visão diferente daquela dos romanos da época, pois sempre visualizamos os domínios

\footnotetext{
${ }^{13}$ Rerum gestarum divi Augusti, quibus orbem terrarum imperio populi Romani subiecit.

${ }^{14}$ Cum divina tua mens et numen, Imperator Caesar, imperio potiretur orbis terrarum.
} 
romanos em relação aos contornos continentais conhecidos hoje. Estes mapas não mostram o mundo que os romanos conheciam.

Sabemos que, por volta de 12 a.C., Agripa mandou preparar um grande mapa do mundo, que foi concluído por Augusto. Tal mapa se localizava no Pórtico Vipsania. ${ }^{15}$ De acordo com R. Moynihan (1985, p. 153), não se sabe exatamente os territórios representados no mapa; nossa melhor fonte para conhecer a existência e conteúdo do mapa de Agripa é a obra de Plínio, o Velho, História Natural. No Livro 3, Plínio escreve que Agripa, um "homem muito esmerado e um geógrafo muito cuidadoso", teve um "mapa do mundo" desenhado, acompanhado de um comentário no qual foram dadas distâncias entre os lugares, o mapa e o comentário sendo gravados no mármore.

Moynihan (1985, p. 154-155) acredita que o mapa de Agripa, embora não tão preciso como um mapa moderno, não era muito impreciso em termos de relações espaciais reais. Provavelmente deve ter sido desenhado de forma alongada, ao longo da parede do pórtico, com dimensões de 30 por 60 pés ${ }^{16}$; e, seguindo a tradição geográfica grega, que Agripa devia conhecer, o mapa deve ter retratado a terra habitável como uma massa de terra oval cercada por oceano e dividida nos três continentes da Europa, Ásia e África. Este autor defende, portanto, que o mapa de Agripa, construído no auge do sucesso militar de Augusto, mostrava o mundo semelhante em forma e tamanho ao proposto por Estrabão (Figura. 2) e seus predecessores.

Figura 2 - O mundo de acordo com Estrabão.

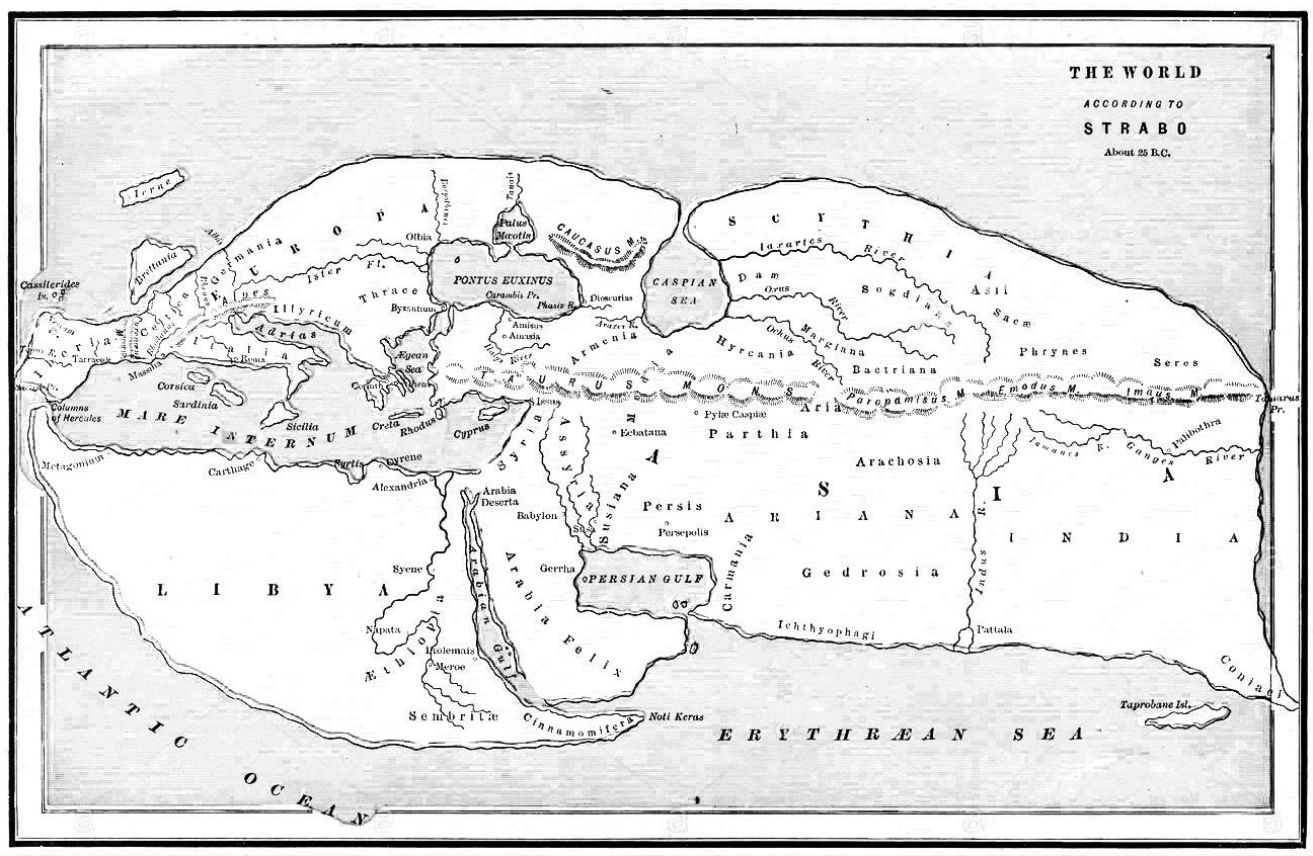

Fonte: Imagem disponível em https://www.alamyimages.fr/photo-image-1889-carte-dumonde-selon-strabon-environ-25-bc-53456241.html. Acessado em: 17 fev. 2020.

\footnotetext{
15 O Pórtico Vipsania foi iniciado por Vipsania Polla, irmã de Agripa, e foi concluído por Augusto após o ano 7 a.C., pois sabemos que o Pórtico ainda estava inacabado quando Augusto dedicou o Campus de Agripa em 7 a.C. (DION CÁSSIO. História Romana, LV, 8, 3-4). Além do mapa do mundo em grande detalhe, ele tinha plantações de louros. Provavelmente estava ao longo do lado sudeste do Campus Agrippae, enquadrando-o e limitando-o (RICHARDSON, 1992, p. 317).

16 Aproximadamente 9 por 18 metros, já que um pé romano equivale a $296 \mathrm{~mm}$.
} 
Apesar de concordar que uma reconstrução precisa do mapa de Agripa seja impossível, Moynihan defende que é possível fazer uma reconstrução útil para entender um pouco sobre a visão de mundo dos romanos. Desta forma, a partir da evidência literária, ele reconstruiu as regiões que fariam parte do mapa, por meio de formas retangulares espalhadas pelo Mediterrâneo, aproximadamente nas posições em que estavam em mapas gregos da época (Figura 3).

Figura 3 - Reconstrução aproximada do mapa de Agripa.

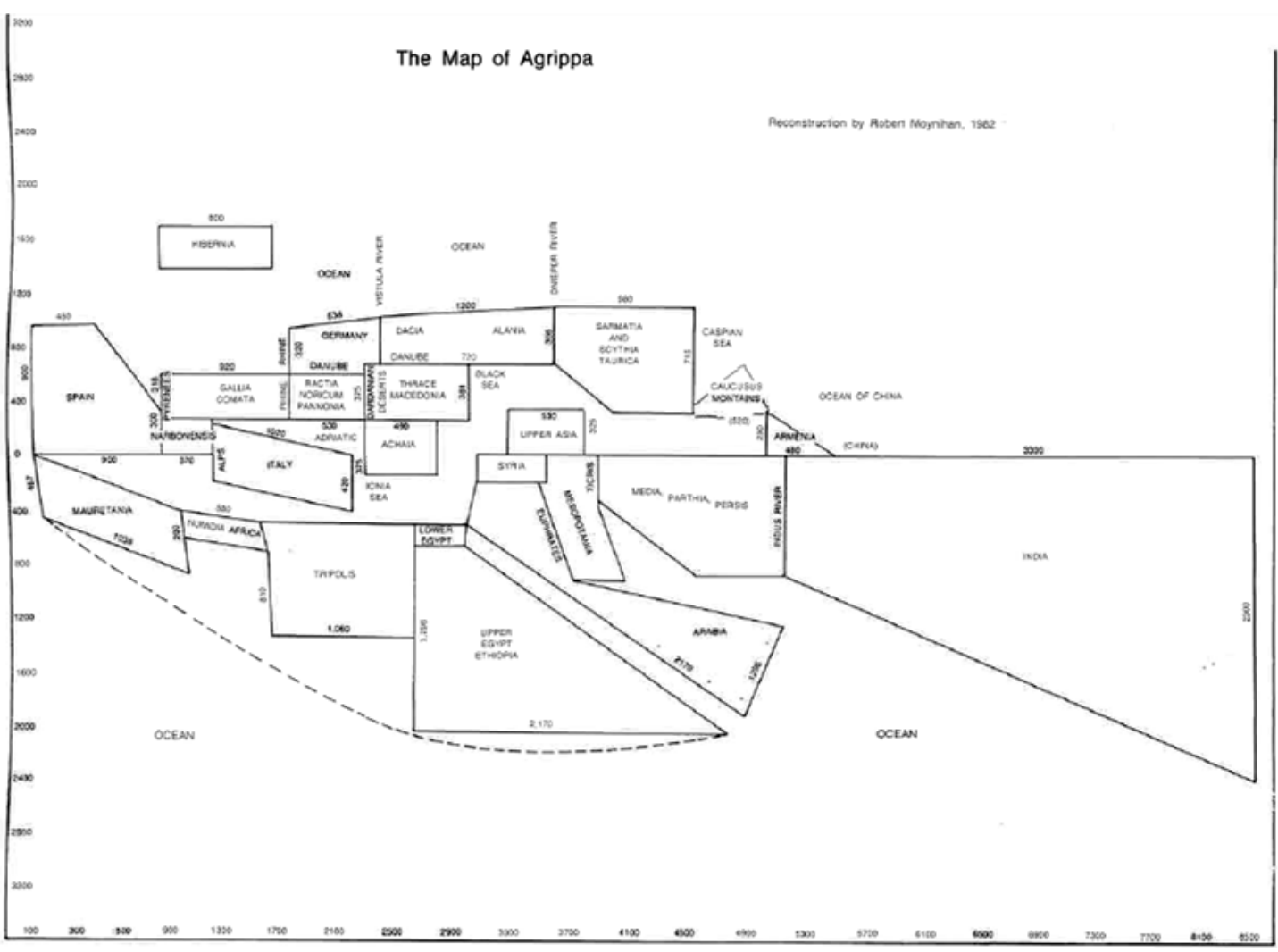

Fonte: MOYNIHAN, 1985, p. 162

Moynihan sugere que:

[...] a visão errônea do tamanho do mundo, refletida no mapa de Agripa, contribuiu diretamente durante o período de Augusto para uma estratégia de conquista mundial e uma ideologia do domínio mundial romano. O mapa de Agripa em si foi um elemento de propaganda imperial. Quão devotamente a mensagem do mapa foi aceita, não podemos saber com certeza, mas o próprio mapa certamente incorporou uma reivindicação oficial da soberania mundial, como Brunt observou. Brunt também apontou que as moedas romanas da época representam a figura da Vitória sentada em um globo; que Augusto escolheu registrar entre seus sucessos mais memoráveis a chegada de embaixadas da Índia e Sarmatia e Scythia; que Augusto admirou Alexandre e trouxe vastos novos territórios ao controle direto do Império, tudo isso sugerindo que Augusto pode ter visado, não uma fronteira frágil e defensiva, mas um literal governo mundial. Para Augusto, uma falsa visão geográfica do mundo, oficialmente sancionada no mapa de Agripa, deve ter feito essa ambição parecer não muito longe da realização (MOYNIHAN, 1985, p. 156). 
Devemos perceber como a confecção e exposição de tal mapa, grafado em mármore, e localizado num pórtico onde haveria grande movimentação de pessoas, foi importante na época e vinha ao encontro da política adotada por Augusto. Tal obra, além de ressaltar a posição privilegiada de Roma como capital do mundo, ainda se utilizava da arquitetura como suporte para a efetiva propaganda relacionada ao poder de Roma sob o governo do Princeps.

\section{CONSIDERAÇÕES FINAIS}

Desta forma, foi elaborada e difundida a noção de que a Roma de Augusto era a capital do mundo conhecido e esta deve ter sido uma crença e uma sensação compartilhada por grande parte da população. Esta crença estava materializada no mapa de Agripa, mas também estava visível no Pórtico Ad Nationes, construído por Augusto e cujo nome aludia ao fato de possuir uma galeria de estátuas representando todas as nações. ${ }^{17}$

Além disso, também estava visível a todos por meio das riquezas advindas através da expansão territorial. Muitas vezes, tal riqueza foi revertida para a construção de majestosos edifícios públicos que ornavam a capital do mundo com a grandiosidade que lhe convinha. Com isso, os habitantes de Roma poderiam usufruir, como vimos anteriormente, da abundância de água trazida pelos aquedutos até as fontes e os banhos públicos, bem como poderiam transitar nos complexos arquitetônicos elaborados com mármores vindos de diversas partes do Império.

Portanto, a cidade de Roma foi utilizada por Augusto como um importante suporte sobre o qual ele, além de edificar e erigir importantes obras arquitetônicas, as utilizava como propaganda política, de modo tal que, a cada novo empreendimento arquitetônico levado a efeito por ele e por pessoas ligadas a ele, mais a sua imagem se unia à imagem de um bom governante, o construtor por excelência, que, com sua política de melhoramento da infraestrutura de Roma, bem como de reforma e construção de edifícios e complexos arquitetônicos monumentais, propiciava a construção material e simbólica da Vrbs enquanto capital do mundo conhecido.

\section{FONTES}

CÍCERO. Da República. Trad. Amador Cisneiros. São Paulo: Escala, 2001.

DIO CASSIUS. Dio's Roman History. Trad. Earnest Cary. Harvard: University Press, 1924. (The Loeb Classical Library).

DIONYSIUS OF HALICARNASSUS. The Roman Antiquities. Trad. Earnest Carry. London: William Heinemann, 1960. (The Loeb Classical Library).

\footnotetext{
${ }^{17}$ Não se tem ideia de quão grande era, onde se localizava, ou como o programa de estátuas teria sido (RICHARDSON, 1992, p. 316-317).
} 
OVID. Fasti. Trad. James G. Frazer. Harvard: University Press, 1931. (The Loeb Classical Library).

PAUSANIAS. Description of Greece. Trad. W. H. S. Jones. Cambridge: Harvard University Press, 1918.

PLINY. Natural History. Trad. W.H.S. Jones London: William Heinemann, 1961. (The Loeb Classical Library).

PLUTARCH. The Life of Antony. In: PLUTARCH. The Parallel Lives. Trad. Bernadotte Perrin. London: William Heinemann, 1919. (The Loeb Classical Library).

RES GESTAE DIVI AUGUSTI. Trad. Frederick W. Shipley. London: Harvard University Press, 1961. (The Loeb Classical Library).

STRABO. Geography. Trad. Horace Leonard Jones. Harvand: University Press, 1923. (The Loeb Classical Library).

SUETONIUS. Life of Augustus. In: SUETONIUS. Lives of the Caesars. Trad. J. C. Rolfe. London: William Heinemann, 1914. (The Loeb Classical Library).

TITUS LIVIUS. History of Rome. Trad. Canon Roberts. London: Everyman's Library Classical, 1905.

VARRO. On the Latin Language, v. I. Cambridge: Harvard University Press, 1951. (The Loeb Classical Library).

VIRGÍLIO. Eneida. Tradução de Carlos A. Nunes. São Paulo: Editora 34, 2016.

VITRÚVIO. Tratado de Arquitetura. Trad. M. Justino Maciel. São Paulo: Martins, 2007.

\section{REFERÊNCIAS:}

ANTAYA, R. The Etymology of Pomerium. The American Journal of Philology, v. 101, n. 2, p. 184-189, 1980.

BEACHAM, R. The Emperor as Impresario: Producing the Pageantry of Power. In. GALINSKY, K. (ed.). The Age of Augustus. New York: Cambridge University Press, 2007. p. 151-174.

BEARD, M.; NORTH, J.; PRICE, S. Religions of Rome. v. 1. Cambridge: Cambridge University Press, 2004.

BOATWRight, M. T. Tacitus on Claudius and the Pomerium, "Annals" 12.23.2-24. The Classical Journal, v. 80, n. 1, p. 36-44, 1984.

BOATWRIGHT, M. T. The Pomerial Extension of Augustus. Historia: Zeitschrift für Alte Geschichte, Bd. 35, H. 1, p. 13-27, 1986.

DROGULA, F. K. Imperium, Potestas, and the Pomerium in the Roman Republic. Historia: Zeitschrift für Alte Geschichte, Bd. 56, H. 4, p. 419-452, 2007.

FAVRO, D. The Urban Image of Augustan Rome. Los Angeles: Cambridge University Press, 2008.

HASELBERGER, L. Urbem Adornare: Rome's urban metamorphosis under Augustus. Pennsylvania: JRA Supp. 64, 2007. 
HOPE, V. The city of Rome: capital and symbol. In: HUSKINSON, J. Experiencing Rome: Culture, Identity and Power in the Roman Empire. New York: Routledge, 2005. p. 63-93.

LABROUSSE, M. Le pomerium de la Rome impériale. Mélanges d'archéologie et d'bistoire, t. 54, p. 165-199, 1937.

LE GOFF, J. História e Memória. Campinas: Ed. da Unicamp, 1996.

LOMAS, K. The Idea of a city: élite ideology and the evolution of urban form in Italy, $200 \mathrm{BC}-\mathrm{AD}$ 100. In: PARKINS, H. M. (ed.). Roman Urbanism: Beyond the consumer city. New York: Routledge, 2005. p. 21-41.

MOYNIHAN, R. Geographical Mythology and Roman Imperial Ideology. In: WINKES, R. The Age of Augustus: Interdisciplinary Conference Held at Brown University. Louvain-La-Neuve: Universite Catholoque de Louvain, 1985. p. 149-162.

MUMFORD, L. A Cidade na História: suas origens, transformações e perspectivas. São Paulo: Martins Fontes, 1998.

NORA, P. Pierre Nora en Les lieux de mémoire. Montevideo: Ediciones Trilce, 2008.

ORLIN, E. Foreign Cults in Republican Rome: Rethinking the Pomerial Rule. Memoirs of the American Academy in Rome, v. 47, p. 1-18, 2002.

PENSABENE, P. Scavi del Palatino 2: Culti, architettura e decorazioni. t. 1. Roma: L'Erma di Bretscneider, 2017.

RICHARDSON, L. A New Topographical Dictionary of Ancient Rome. London: Johns Hopkins University Press, 1992.

ROBINSON, O. F. Ancient Rome: City planning and administration. London; New York: Routledge, 1994.

WISEMAN, T. P. The Palatine, from Evander to Elagabalus. Journal of Roman Studies, v. 103, p. 234-268, 2013. 